\title{
Comprehensive Analysis of Complement Genes in Patients with Atypical Hemolytic Uremic Syndrome
}

\author{
Tao Zhang Jianping Lu Shaoshan Liang Dachen Chen Haitao Zhang \\ Caihong Zeng Zhihong Liu Huimei Chen
}

National Clinical Research Center of Kidney Diseases, Jinling Hospital, Nanjing University School of Medicine, Nanjing, China

\begin{abstract}
Key Words
Atypical hemolytic uremic syndrome - Chinese .

Complement - Mutation · Phenotype
\end{abstract}

\begin{abstract}
Background: Genetic defects in complement proteins reportedly contribute to the atypical hemolytic uremic syndrome (aHUS). Numerous genetic studies have been published in recent years, but limited data have been gathered from Asian countries. Methods: Genetic variants of $11 \mathrm{com}$ plement genes were analyzed in 23 Chinese patients with aHUS by high-throughput sequencing. The genotype-phenotype relationship in the Han population was evaluated and compared with the relationship that existed in other ethnicities. Results: We identified 20 causative mutations in complement genes, including 19 missense mutations and 1 splicing mutation. Six previously reported mutations, $6 \mathrm{mu}$ tations detected for the first time, and 8 rare polymorphisms were noted. Twelve out of 23 patients harbored complement mutations. Among the patients, one was a homozygote (Arg142Cys in CFHR3), and 4 carried combined mutations. Chinese patients have a similar prevalence of complement mutations as European, Japanese, and American patients. Complement factor $\mathrm{H}$ (CFH) mutations were common in aHUS in different ethnicities, but Chinese patients exhibited a higher percentage of complement factor B mutations than were found in European patients and a lower percentage of component 3 (C3) mutations than in Japanese
\end{abstract}

patients. Compared with non-carriers, the aHUS patients carrying mutations had reduced C3 levels. In particular, patients with CFH mutations had a worse renal function than those with membrane cofactor protein mutations, a higher level of serum creatinine at the disease onset and a higher percentage of renal insufficiency during follow-up. Conclusions: Because complement genetic dysfunction has clinical significance in aHUS, a comprehensive assessment of variants is necessary for the proper management of aHUS patients in China.

(c) 2016 S. Karger AG, Basel

\section{Introduction}

Atypical hemolytic uremic syndrome (aHUS) is a rare disease characterized by microangiopathic hemolysis, thrombocytopenia, and renal failure [1]. The condition has a poor prognosis. In total, $25 \%$ of patients die in the acute phase, and $50 \%$ of patients progress to end-stage renal disease (ESRD) [2]. This disease is reportedly associated with uncontrolled activation of the complement pathway [3-5]. Genetic mutations play a role in such activation, and more than half the number of patients with aHUS have causative mutations in complement genes [6]. Both loss-of-function mutations in regulators (comple-

\section{T.Z. and J.L. contributed equally to this work}

Huimei Chen, MD, PhD or Z Liu, MD

National Clinical Research Center of Kidney Diseases Jinling Hospital, Nanjing University School of Medicine Nanjing 210093 (PR China)

E-Mail chenhuimei@nju.edu.cn or liuzhihong@nju.edu.cn 
ment factor $\mathrm{H}(\mathrm{CFH})$, complement factor I (CFI), membrane cofactor protein (MCP) and thrombomodulin (THBD)) and gain-of-function mutations in key complement components (complement component 3 (C3) and complement factor $\mathrm{B}(\mathrm{CFB})$ ) predispose individuals to aHUS [7]. The genotype-phenotype correlations of aHUS have clinical significance in predicting renal recovery and transplant outcomes [8].

In a recent large genetic screen of 794 aHUS patients, mutations in $\mathrm{CFH}, \mathrm{C} 3, \mathrm{CFI}, \mathrm{CFB}$, or CD46 were identified in $41 \%$ of patients, and combinations of mutations were noted in 3\% of patients [8]. Single nucleotide polymorphisms (SNPs), haplotypes, genetic intervals and fusions in complement genes are also suggested to be involved in the occurrence of aHUS [9]. Various additional genetic contributions to this disease have been reported [10]. These studies clearly implicate mutations in complement genes in the pathogenesis of aHUS. However, most studies are from Western countries and are focused on Caucasians. It is very important to validate these finding in Asia because the human genome has high ethnic variation. Moreover, physical differences and physiological differences are noted between people from Asia and people from other parts of the world [11]. There are even differences in features between people from northern and southern China. The distinct prevalence of chronic kidney diseases in China has also been noted [12].

We enrolled 23 sporadic patients with aHUS from Eastern China. Using targeted genomic enrichment and massively parallel sequencing (TGE + MPS), we conveniently screened the coding sequences and splice sites of 11 reported candidates of complement genes. We then filtered and prioritized variants based on frequency and functional effects. As expected, we identified novel deleterious variants in multiple complement genes. We also determined the genetic features in Chinese patients from different ethnicities.

\section{Subjects and Methods}

\section{Subjects}

Twenty-three Chinese patients with aHUS were recruited from the Renal Disease Biobank of the Research Institute of Nephrology, Jinling Hospital. All cases were hospitalized and underwent renal biopsy for diagnosis in this institute from 2000 to 2012. Diagnosis of aHUS was defined by the simultaneous occurrence of microangiopathic hemolytic anemia, thrombocytopenia and acute renal failure without being associated with Shigatoxin [13, 14]. This study was performed with the written informed consent of all patients and family members, and the procedure was approved by the Ethics Committee of Nanjing University, School of Medicine.
Clinical events preceding the acute aHUS episodes were recorded, and laboratory data were collected before treatments with immunosuppressive agents or plasma exchanges. Acute kidney injury (AKI) is defined as an increase in serum creatinine (SCr) of $\geq 0.3 \mathrm{mg} / \mathrm{dl}(26 \mu \mathrm{mol} / \mathrm{l})$ within $48 \mathrm{~h}$ or $\geq 1.5$ times baseline, which is known or presumed to have occurred within the prior 7 days, or urine volume of $0.5 \mathrm{ml} / \mathrm{kg} / \mathrm{h}$ or less for $6 \mathrm{~h}$. Glomerular filtration rate was estimated (eGFR) using the simplified Modification of Diet in Renal Disease formula [15]. All cases were regularly followed up at the out-clinic until December 1, 2014. During followup, ESRD was defined as eGFR $<15 \mathrm{ml} / \mathrm{min} / 1.73 \mathrm{~m}^{2}$ or requirement of dialysis. If a patient presented $\mathrm{AKI}$, renal remission was defined as SCr $<1.6 \mathrm{mg} / \mathrm{dl}(141 \mu \mathrm{mol} / \mathrm{l})$.

\section{DNA Extraction and Targeted Exon Sequencing}

Genomic DNA was extracted from peripheral blood using the GentraPure gene kit (Qiagen Inc., Valencia, Calif., USA). RefSeq coding exons of the following genes were targeted with an extra 100 bases upstream and downstream: C3 (NM_000064), MCP (NM_002389), CFB (NM_001710), CFH (NM_000186), CFHR1 (NM_002113), CFHR2 (NM_005666), CFHR3 (NM_021023), CFHR4 (NM_006684), CFHR5 (NM_030787), CFI (NM_000204) and THBD (NM_000361). Detailed information for capture design, sequence capture, library preparation and Ion Torrent sequencing is available in the online supplementary methods (for all online suppl. material, see www.karger.com/doi/10.1159/000445127).

After sequencing, the mean reads generated per sample was 435,861 , with quality control of $89-93 \%$. The total number of bases per sample was approximately $60.9 \mathrm{Mbp}$, and the mean length of a read was $132 \mathrm{bp}$. The longest read was $370 \mathrm{bp}$.

\section{Variant Calling and Mutation Polarization}

The flowchart of variant calling and mutation polarization is presented in online supplementary figure S1. A total of 2,237 (of 2,$609 ; 85.74 \%$ ) variants passed quality control, and 895 had nonsynonymous substitutions, frame shifts, splicing site changes, or indel variations. The called variants were further reviewed in databases and analyzed in 100 local healthy controls. Commons variants were excluded, which were defined as variants with a minor allele frequency (MAF) value of $>3 \%$ in the Asian population based on the 1000 Genomes Project (April 2012) or a frequency of $>1 \%$ in the local control cohort [16].

The polarized variants were confirmed by Sanger Sequencing and then considered causative mutations (online suppl. fig. S2). The variants were further divided into 3 subtypes: disease-related mutations, novel mutations and rare polymorphisms. Here, a disease-related mutation is a pathogenic mutation reportedly related to certain diseases. No novel mutations were found in the 1000 Genomes data, the National Center for Biotechnology Information dbSNP database, or the local cohort. A rare polymorphism was detected in $\leq 3 \%$ of the Asian population based on the 1000 Genomes Project (April 2012) and in $\leq 1 \%$ of the local control cohort.

In addition, the potential pathogenicity of these causative mutations was multiply predicted by 5 methods in silico, including SIFT (http://sift.jcvi.org), Align-GVGD (http://agvgd.iarc.fr/), PMut (http://mmb.pcb.ub.es/PMut/), SNAP (https://rostlab.org/ services/snap/), and PolyPhen2.0 (http://genetics.bwh.harvard. $\mathrm{edu} / \mathrm{pph} 2 / \mathrm{dbsearch} . \mathrm{shtml}$ ). A mutation was predicted to be pathogenic if it was positive in 3 or more of the methods. 
Literature Review

Reported mutations associated with aHUS in complement genes were further reviewed. The PubMed database was searched for published cohort studies up to December 5, 2014 using the combination of the following key words: 'mutation', 'cohort', 'alternative', 'complement' and 'aHUS'. Relevant studies with cohorts screened for more than 5 complement genes in aHUS patients were enrolled. Finally, the 3 cohorts from Europe, America and Japan were reviewed (online suppl. table S1) and further compared with our Chinese cohort.

\section{Statistical Analyses}

Data were analyzed using SPSS 19.0. The t test or the MannWhitney test was used to compare means. Data are displayed as the mean \pm SD or medians and interquartile ranges. Chi-square tests were performed for qualitative data, and the data were expressed as percentages (\%) in a group. The renal survival rate was analyzed with Kaplan-Meier analysis. p values $<0.05$ were considered significant.

\section{Results}

All study participants were of the Han descent in China. The mean age of our patients with aHUS was $35.8 \pm 13.6$ (range 13.0-60.5). The study included 10 men and 13 women (table 1). All patients presented with acute renal failure and microangiopathic hemolytic anemia, and $69.6 \%$ had thrombocytopenia. The typical lesions in the kidney were platelet-fibrin rich microthrombi causing small vessel thrombosis, schistocytosis, and thrombotic microangiopathy (online suppl. fig. S3). Strong C3 staining was observed in the mesangial area of the glomeruli. No family history of aHUS or kidney disease was reported. With a mean follow-up of 8.3 months, 11 $(47.8 \%)$ patients progressed to ESRD.

\section{Mutation Identification}

After 11 complement genes were screened in these 23 patients, a total of 19 nonsynonymous variants and 1 splicing variant were identified in these aHUS patients (online suppl. fig. S1). These mutations were located in 9 genes with an average 1.82 (range $0-4$ ) mutations per gene (fig. 1a). Four mutations were identified in $\mathrm{C} 3$ at macroglobulin domain 1-3, a domain for binding to complement regulator factors (fig. 1b). Complement genes often contain short consensus repeats (SCRs) [1, $17,18]$. Three mutations in MCP were located at the Nterminus and in SCR2/SCR3 (fig. 1c). Three mutations in CFB were located at its SCR1 and serine protease (SP) site in the C-terminus (fig. 1d). The $\mathrm{CFH}$ gene and the genes encoding the 5 CFHR proteins reside in the centromere, a $355-\mathrm{kb}$ segment on chromosome 1q32, and
Table 1. The demonstration and clinical profile of patients with aHUS

\begin{tabular}{lc}
\hline Characteristic & aHUS \\
\hline Patients, $\mathrm{n}$ & 23 \\
Male, $\mathrm{n}(\%)$ & $10(43.5)$ \\
Age, years & $35.9(23.0-41.3)$ \\
AKI, $\mathrm{n}(\%)$ & $23(100)$ \\
Anemia, $\mathrm{n}(\%)$ & $23(100)$ \\
Thrombocytopenia, $\mathrm{n}(\%)$ & $16(69.6)$ \\
Hypertension, $\mathrm{n}(\%)$ & $16(69.6)$ \\
Family history, $\mathrm{n}(\%)$ & 0 \\
Urine protein, g/24 h & $0.87(0.52-2.79)$ \\
Erythrocyturia, $\times 10^{4} / \mathrm{ml}$ & $15.5(2.5-165)$ \\
SCr, $\mu$ mol/l & $770.6 \pm 479.3$ \\
eGFR, ml/min/1.73 m ${ }^{2}$ & $11.64 \pm 9.98$ \\
Complement C3 level, g/l & $0.73 \pm 0.19$ \\
Follow-up duration, months & $8.3(2.2-23.3)$ \\
Renal survival rate, $\mathrm{n}(\%)$ & $12(52.2)$ \\
\hline
\end{tabular}

they were clustered as CFH family genes $[19,20]$. A total of 8 mutations were identified in the CFH family genes, and the mutations were mainly located in the domains for binding to $\mathrm{C} 3$ and heparin-like oligosaccharides (fig. 1e).

Among the 20 causative mutations, 6 were disease-related mutations, 6 were novel as aHUS mutations, and 8 were rare polymorphisms (table 2). Four disease-related mutations (p.Thr162Arg in C3, p.Lys533Arg in CFB, p.Leu1189Phe in CFH and p.Arg1215Gly in CFH) were causally related to aHUS $[8,21-23]$, and 2 (p.Pro314Leu and p.Arg102Gly in C3) were reportedly associated with age-related macular degeneration (AMD) $[24,25]$. AMD is heritable and also strongly associated with complement dysfunction [26]. Eight rare polymorphisms had an average MAF of $0.0078 \pm 0.0100$ (range $0.0034-0.0288$ ) in 2,500 subjects from 1000 genomes (http://www.ncbi.nlm. nih.gov/projects/SNP). Their percentage in our control cohort was $0.00375 \pm 0.0044$ (range $0.00-0.01$ ). Six novel mutations were not reported and not detected in the control cohort, either. In addition, 9 (45\%) of 20 mutations were predicted to be deleterious, including 4 ( $66.7 \%$; of 6$)$ disease-related, 2 (33.3\%; of 6$)$ novel and 3 (37.5\%; of 8 ) rare variants.

\section{Mutation Prevalence}

In this study, 12 (52.2\%) of 23 cases in Chinese patients with aHUS were associated with complement mutations (fig. 2a). Eight (34.8\%) patients carried one complement mutation, and $4(17.3 \%)$ patients carried combined muta- 


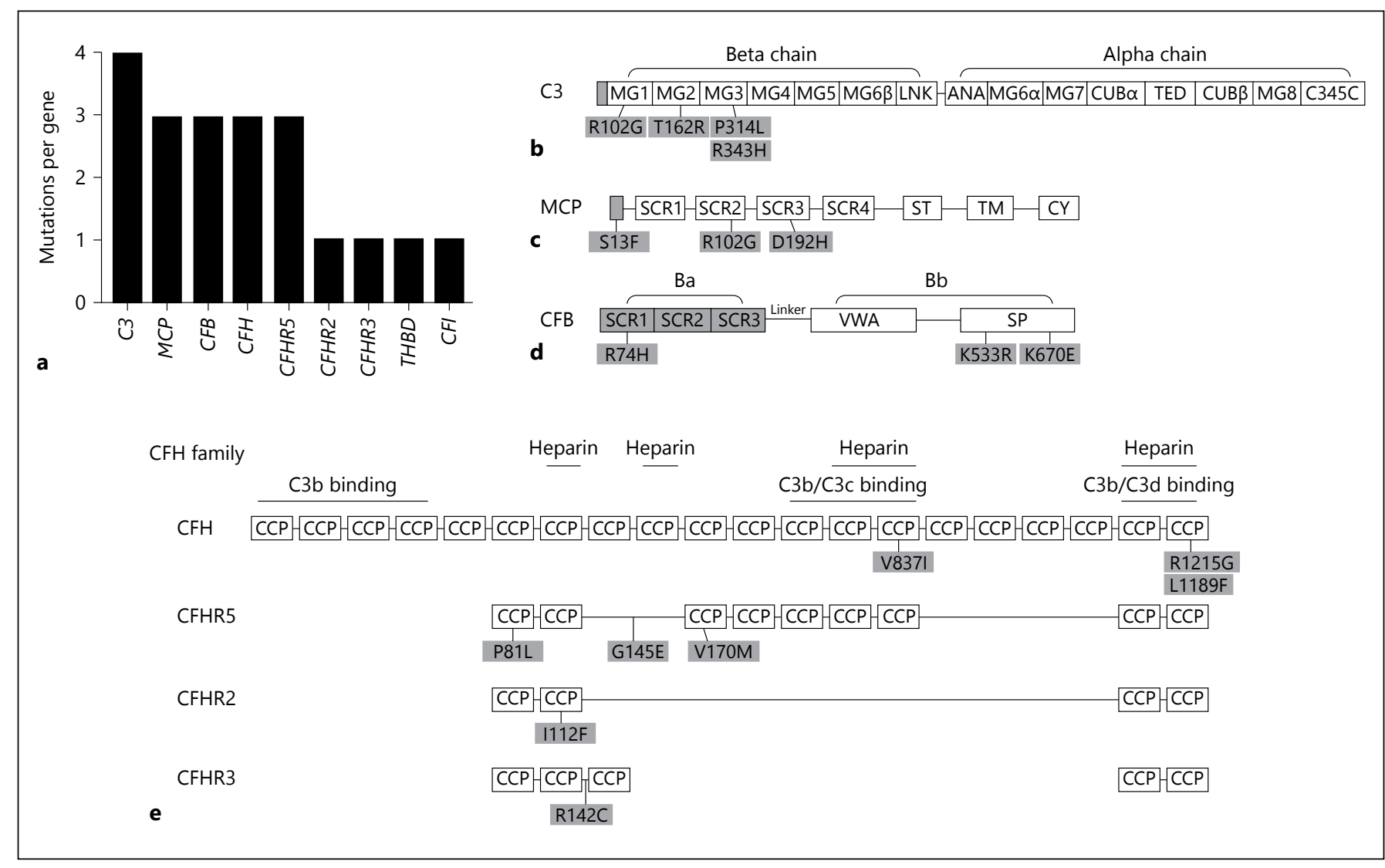

Fig. 1. The quantity and localization of the causative mutations identified in the aHUS patients. a The numbers of mutations screening 9 genes of alternative complement pathway in 23 aHUS patients. b-e Localization of the mutations in CFH family, MCP, $\mathrm{C} 3$, and CFB which were found in 12 patients with single mutations or combined gene mutations from Chinese cohorts. tions. The combinations found were in different genes in each patient (fig. 2b). One patient harbored combined mutations in CFH and CFHR5, and another patient had mutations in MCP, THBD and CFI. Two patients harbored 4 mutations each. One carried p.Pro314Leu, p.Arg102Gly and p.Arg343His in the C3 gene and p.Lys533Arg in CFB. One patient carried all 4 mutations from different genes in the CFH family. Only 1 patient was homozygous for a mutation in CFHR3 (p.Arg142Cys); others were heterozygous. The p.Ser13Phe mutation in $\mathrm{MCP}$ was detected in 2 patients and other mutations were found in 1 patient.

To demonstrate the complement mutations in different ethnic groups, the reported cohorts of aHUS from Europeans $(\mathrm{n}=795)$, Japanese $(\mathrm{n}=10)$ and Americans $(\mathrm{n}=144)$ were reviewed (online suppl. table S1) $[8,11$, 18]. Our cohort was recalculated with different sets of 5 , 6 and 7 genes screened, making it comparable with others (table 3 ). In general, $~ 50 \%$ of Chinese patients presented complement mutations, and the prevalence in European, American and Japanese patients were 41,46 and $80 \%$, respectively.

Mutations in CFH were common in aHUS, and 13.0 $27.1 \%$ of patients carried CFH mutations in different ethnic groups. The percentage of CFB mutations was higher in Chinese than that found among Europeans (13.0 vs. $1.1 \%, \mathrm{p}=0.01)$ and Americans ( 13.0 vs. $4.2 \%, \mathrm{p}=0.11$ ). However, no CFB mutation was detected in the Japanese patients. MCP mutations were noted in $17.4 \%$ of Chinese and $20.0 \%$ of Japanese patients but only in $8.2 \%$ of Europeans and $4.9 \%$ of Americans. The Asian groups exhibited increased MCP mutation levels compared with the Western groups $(21.2$ vs. $7.4 \%, p=0.01)$. When 5 genes were screened, the Chinese exhibited a similar percent of combined mutations as Europeans (8.7 vs. 3.4\%, $\mathrm{p}=0.19)$. However, when 7 genes were screened, Chinese patients exhibited a higher percentage of combined mutations than Americans (17.4 vs. $5.6 \%, \mathrm{p}=0.06$ ). 
Table 2. Causative mutations identified in aHUS patients

\begin{tabular}{|c|c|c|c|c|c|c|c|c|}
\hline Nucleotide & Gene & Genotype & Patient & AA change & dbSNP & MAF & Location & Prediction \\
\hline \multicolumn{9}{|c|}{ Reported disease-related variants } \\
\hline c. $941 \mathrm{C}>\mathrm{T}$ & $\mathrm{C} 3$ & Heterozygous & ADB81 & Pro314Leu & rs1047286 & 0.0699 & MG3 & 1 \\
\hline c. $304 \mathrm{C}>\mathrm{G}$ & $\mathrm{C} 3$ & Heterozygous & ADB81 & Arg102Gly & rs2230199 & 0.0873 & MG1 & 1 \\
\hline c. $485 \mathrm{C}>\mathrm{G}$ & $\mathrm{C} 3$ & Heterozygous & ADB69 & Thr162Arg & NA & NA & MG2 & 1 \\
\hline c. $1598 \mathrm{~A}>\mathrm{G}$ & $\mathrm{CFB}$ & Heterozygous & ADB81 & Lys533Arg & rs149101394 & 0.0192 & SP & 0 \\
\hline c. $3565 \mathrm{C}>\mathrm{T}$ & $\mathrm{CFH}$ & Heterozygous & ADB71 & Leu1189Phe & NA & NA & SCR20 & 0 \\
\hline c. $3643 C>G$ & $\mathrm{CFH}$ & Heterozygous & ADB67 & Arg1215Gly & NA & NA & SCR20 & 1 \\
\hline \multicolumn{9}{|c|}{ Rare polymorphisms } \\
\hline c. $1028 \mathrm{G}>\mathrm{A}$ & $\mathrm{C} 3$ & Heterozygous & ADB81 & Arg343His & rs373511900 & NA & MG3 & 0 \\
\hline c. $221 \mathrm{G}>\mathrm{A}$ & CFB & Heterozygous & ADB74 & Arg74His & rs117314762 & 0.0010 & SCR1 & 1 \\
\hline c. $2509 \mathrm{G}>\mathrm{A}$ & $\mathrm{CFH}$ & Heterozygous & ADB82 & Val837Ile & rs55807605 & 0.0034 & SCR16 & 0 \\
\hline c. $424 \mathrm{C}>\mathrm{T}$ & CFHR3 & Homozygous & ADB82 & Arg142Cys & rs61737525 & 0.0288 & Unstructured region & 1 \\
\hline c. $434 \mathrm{G}>\mathrm{A}$ & CFHR5 & Heterozygous & ADB82 & Gly145Glu & rs57960694 & 0.0107 & Unstructured region & 0 \\
\hline c. $508 \mathrm{G}>\mathrm{A}$ & CFHR5 & Heterozygous & ADB67 & Val170Met & rs201073457 & 0.0012 & SCR3 & 1 \\
\hline c. $293 \mathrm{C}>\mathrm{T}$ & MCP & Heterozygous & ADB72 & Thr98Ile & rs116800126 & 0.0010 & SCR2 & 0 \\
\hline c. $38 \mathrm{C}>\mathrm{T}$ & MCP & Heterozygous & $\begin{array}{l}\text { ADB88 } \\
\text { ADB73 }\end{array}$ & Ser13Phe & rs138843816 & 0.0086 & N-terminal & 0 \\
\hline \multicolumn{9}{|c|}{ Rare polymorphisms identified in this study } \\
\hline c. $2008 \mathrm{~A}>\mathrm{G}$ & CFB & Heterozygous & ADB84 & Lys670Glu & NA & NA & SP & 0 \\
\hline c. $242 \mathrm{C}>\mathrm{T}$ & CFHR5 & Heterozygous & ADB83 & Pro81Leu & NA & NA & SCR1 & 1 \\
\hline c. $335 \mathrm{~A}>\mathrm{T}$ & CFHR2 & Heterozygous & ADB82 & Ile112Phe & NA & NA & SCR1 & 0 \\
\hline c. $574 \mathrm{G}>\mathrm{C}$ & MCP & Heterozygous & ADB78 & Asp192His & NA & NA & SCR3 & 0 \\
\hline c. $1336 \mathrm{G}>\mathrm{A}$ & THBD & Heterozygous & ADB78 & Glu446Lys & NA & NA & EGFD5 & 0 \\
\hline c. $904+1 G>A$ & CFI & Heterozygous & ADB78 & Splicing & NA & NA & NA & 1 \\
\hline
\end{tabular}

The MAF from 1000 genomes is referred in http://www.ncbi.nlm.nih.gov/projects/SNP.

$\mathrm{EGFD}=$ Epidermal growth factor domain; NA = not available.

\section{Clinical Findings}

aHUS patients were divided into two groups, mutation carriers and non-carriers, based on the presence or absence of complement mutations (table 4). Compared with non-carriers, patients carrying mutations presented with a significantly lower level of C3 (0.65 vs. $0.81 \mathrm{~g} / \mathrm{l}, \mathrm{p}=0.04)$. Patients carrying mutations also had relatively young onset ages, a high percentage of thrombocytopenia, increased SCr, and decreased levels of platelet and hemoglobin. However, these characters did not reach statistical significance between 2 groups.
All patients with aHUS presented with AKI at onset, and approximately half the number of patients experienced remission after treatment (table 4). The rate of remission was similar between patients with and without mutations ( $p=0.4)$. During follow-up, the carriers seemed to have better prognosis than non-carriers (fig. 3a). However, this value did not reach statistical significance, partly given the small size of our cohort.

Five $(62.5 \%$, of 8$)$ patients with a single mutation exhibited the gradual recovery of renal function and they remained stable during follow-up. However, for those carrying combined mutations, only one $(25.0 \%$, of 4$)$ patient 
Table 3. Gene profile of Chinese aHUS patients compared with those of Caucasians and Japanese cohorts

\begin{tabular}{|c|c|c|c|c|c|c|c|c|c|}
\hline \multirow{2}{*}{$\begin{array}{l}\text { Genes screened } \\
\text { Ethics }\end{array}$} & \multicolumn{3}{|c|}{$\mathrm{CFH}, \mathrm{C} 3, \mathrm{CFB}, \mathrm{CFI}$ and $\mathrm{MCP}$} & \multicolumn{3}{|c|}{$\begin{array}{l}\text { CFH, C3, CFB, CFI, MCP and } \\
\text { THBD }\end{array}$} & \multicolumn{3}{|c|}{$\begin{array}{l}\text { CFH, C3, CFB, CFI, MCP, THBD } \\
\text { and CFHR5 }\end{array}$} \\
\hline & Chinese & European [8] & $\mathrm{p}$ value & Chinese & Japanese [11] & $\mathrm{p}$ value & Chinese & American [18] & $\mathrm{p}$ value \\
\hline Cohort number & 23 & 795 & & 23 & 10 & & 23 & 144 & \\
\hline Mutation prevalence, $\mathrm{n}(\%)$ & $11(47.8)$ & $323(40.6)$ & 0.49 & $11(47.8)$ & $8(80.0)$ & 0.13 & $12(52.2)$ & $66(45.8)$ & 0.57 \\
\hline \multicolumn{10}{|c|}{ Individual gene, $\mathrm{n}(\%)$} \\
\hline CFB & $3(13.04)$ & $9(1.13)$ & 0.01 & $3(13.0)$ & $0(0.00)$ & 0.54 & $3(13.04)$ & $6(4.17)$ & 0.11 \\
\hline CFI & $1(4.35)$ & $46(5.79)$ & 1.00 & $1(4.35)$ & $0(0.00)$ & 1.00 & $1(4.35)$ & $12(8.33)$ & 1.00 \\
\hline MCP & $4(17.39)$ & $65(8.18)$ & 0.12 & $4(17.4)$ & $2(20.0)$ & 1.00 & $4(17.39)$ & $7(4.86)$ & 0.04 \\
\hline THBD & - & - & - & $1(4.35)$ & $1(10.0)$ & 0.52 & $1(4.35)$ & $4(2.78)$ & 0.53 \\
\hline CFHR5 & - & - & - & - & - & - & $3(13.04)$ & $4(2.78)$ & 0.06 \\
\hline $\begin{array}{l}\text { Combined mutation } \\
\text { prevalence, } \mathrm{n}(\%)\end{array}$ & $2(8.70)$ & $27(3.40)$ & 0.19 & $2(8.70)$ & $0(0.00)$ & 1.00 & $4(17.39)$ & $8(5.56)$ & 0.06 \\
\hline
\end{tabular}

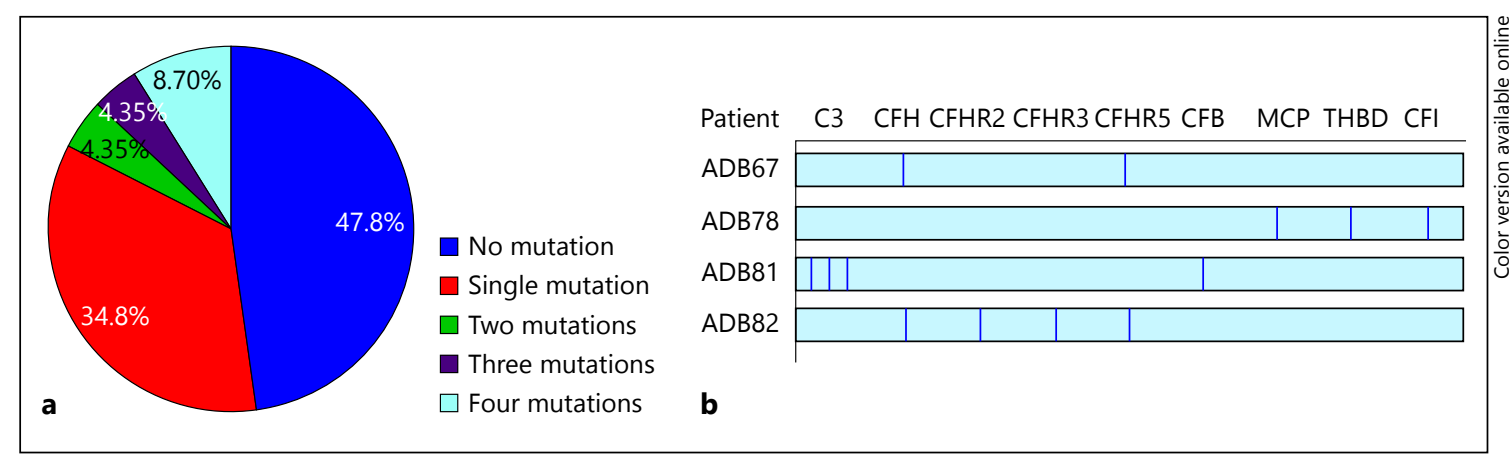

Fig. 2. Distribution of different numbers of causative mutations identified in the aHUS patients of this study. a Eleven (47.8\%) patients did not carry the gene mutations of complement alternative pathway, $8(34.8 \%)$ patients carried single mutation, 1 patient car-

showed remission with immunosuppressive treatment. Two patients even required permanent renal replacement therapy. Two patients carried the same mutation (p.Ser13Phe in MCP), but they had different outcomes.

In addition, patients with CFH mutations and MCP mutations were further compared in table 4. Patients with $\mathrm{CFH}$ mutations exhibited increased levels compared to those with MCP mutations at onset $(1,465 \pm 220$ vs. $822 \pm$ $246 \mu \mathrm{mol} / \mathrm{l}, \mathrm{p}=0.01)$. Two patients with CFH mutations suffered from anuria, and urine protein could not be compared between the 2 groups. After follow-up at 90 months, all patients with CFH mutation developed ESRD, but only $1(25 \%)$ patient with an MCP mutation developed this condition. This difference was not statistically significant ( $p=0.17$; fig. $3 b)$.

Phenotype and Genotype of aHUS ried 2 mutations, another patients carried 3 mutations and the last 2 patients carried 4 combined mutations, respectively. A detailed description of the combined variants in 4 patients is given in (b).

\section{Discussion}

In this study, 23 sporadic Chinese patients with aHUS had 11 complement genes systematically screened with efficient TGE + MPS. After polarization and validation, we identified 20 causative mutations in $52.2 \%$ of patients. In total, $30 \%$ of the mutations were reportedly causative, indicating that these mutations are pathogenic for aHUS. The remaining 14 mutations, including 8 rare polymorphisms and 6 novel mutations, were considered to be causative based on the findings of the prediction programs, a literature review and prevalence of the mutations in population databases and a control cohort.

Approximately half of the Chinese patients with aHUS carried complement mutations, and a similar prevalence 
Table 4. Clinical profile of aHUS patients with different genetic characteristics in alternative complement genes

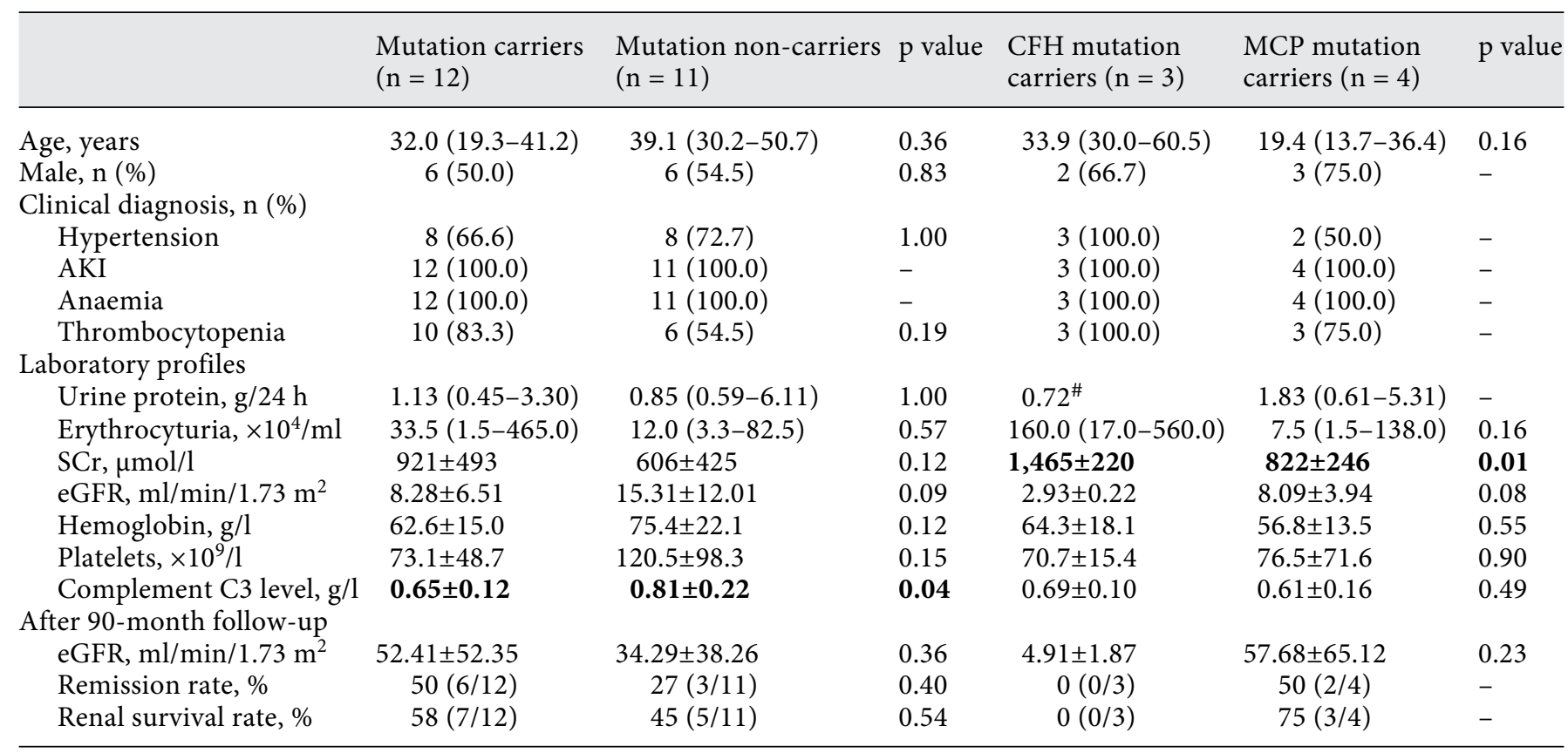

\# Two CFH mutation carriers were progressing to complete anuria at onset.

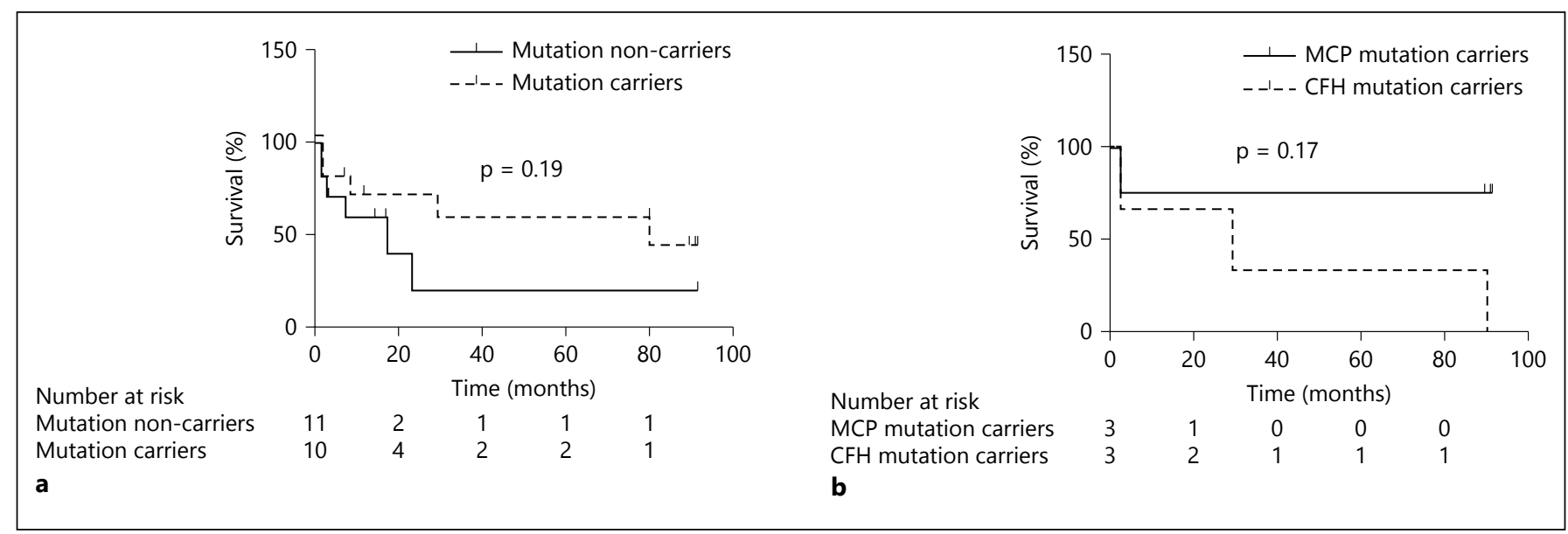

Fig. 3. Association of carried mutations and renal survival. a $\mathrm{Pa}$ tients with aHUS were divided into 2 groups by mutation carriers or non-carriers and the renal survival of 2 groups followed up 90 months was not significantly different $(\mathrm{p}=0.19)$. b No statistical difference was observed between CFH mutation carriers and MCP mutation carriers $(\mathrm{p}=0.17)$. was observed in different ethnic groups. Although the screened genes were different and the cohort sizes were not comparable among reported cohorts, these primary data still confirmed that inherited defects play a pivotal role in the pathogenesis of this disease. One-third of patients with aHUS carried combined mutations and one
Chinese patient even had 4 mutations in different $\mathrm{CFH}$ family genes. This observation implies that the synergistic effects of multiple mutations contribute to aHUS. We proposed that screening of more associated genes be done in order to enable better patient care. High-throughput sequencing is an approach that is increasingly used to an- 
alyze related genes in the field of genetic studies. However, we did not identify gene insertions or deletions, which were occasionally reported in previous studies using multiplex ligation-dependent probe amplification $[1,9]$.

Considering the mutation percentages in individual complement gene, the mutations were mainly identified in the C3, MCP, CFB and CFH families. This issue appeared universal and was also reported among the Americans, Europeans and Japanese $[8,11,18]$. Only a few mutations were noted in CFI and THBD $[27,28]$, and no causative CFHR1/CFHR4 mutations were detected in Chinese patients. However, the percentages of CFI mutations were inconsistent. It was suggested that $4-10 \%$ of aHUS patients from Western populations carried CFI mutations [1], and $4.3 \%$ of our Chinese patient carried these mutations. However, Le Quintrec et al. reported that $16 \%$ of aHUS from a French registry carried CFI mutations [29].

C3 plays a major role in the complement system. C3 contains 8 macroglobulin domains (MG1-8) to form $\alpha$ and $\beta$-chains (fig. 2a). Mutations in C3 reportedly account for the increased complement activation on platelets and glomerular endothelium $[30,31]$ and the etiology of $2-10 \%$ of the aHUS patients [1]. In this study, Chinese aHUS patients carried 4 different missense mutations in C3. These mutations were clustered in the MG1-3 domain, which is located in the $\beta$-chains. This domain is not the classic active domain; it is the domain that binds to complement regulator factors [32]. The p.Pro314Leu and p.Arg102Gly mutations have previously been reported in a Dutch bacterial meningitis cohort and in Icelanders [33], and the mutations are known to enhance complement activation by reducing the binding of $\mathrm{C} 3 \mathrm{~b}$ and $\mathrm{CFH}$.

$\mathrm{MCP}$, a membrane-bound complement regulator highly expressed on most cell surfaces, acts as a cofactor of the CFI-mediated degradation of C3b and C4b. The 4 extracellular SCRs are the binding sites for C3b (fig. 2c), and $3 \mathrm{mu}-$ tations identified in this study were found at those sites. Approximately $10-15 \%$ of the aHUS patients reportedly carried MCP mutations, and SCR-3 was the most affected domain previously reported [34]. The p.Thr98Ile and p.Ser13Phe mutations have been detected in Caucasian and Japanese patients [11], leading to a quantitative defect in a secreted, nonfunctional protein [35].

Mutations in CFB, which resulted in chronic alternative-pathway activation, accounted for the etiology in $1-2 \%$ of the aHUS patients [3]. CFB is composed of 3 complement control protein domains (CCP1-3), a von Willebrand type A domain, and an SP domain (fig. 2d).
In this study, one mutation was located in the CCP domains, and 2 mutations were found in the SP domain. Gain-of-function mutations and formation of the $\mathrm{C} 3 \mathrm{bB}$ proenzyme have been reported in CFB [27]. The p.Lys533Arg and p.Arg74His mutations have previously been reported in French patients [21], and these mutations caused excess C3b affinity and hyperactive C 3 converses as well as enhanced C3b formation [36].

$\mathrm{CFH}$, a principal regulator of the complement system, is composed of 20 SCR domains (fig. 2e). Deficiency of $\mathrm{CFH}$ is commonly associated with aHUS. Greater than $70 \%$ aHUS cases were detected with CFH mutations or anti-CFH autoantibodies [37, 38]. Missense mutations in the $\mathrm{CFH}$ family genes were most frequently identified in CFHR5, and mutations in CFHR1-4 have rarely been reported $[39,40]$. Eight mutations of CFH family were identified in Chinese aHUS patients. Most CFH mutations are located at the $\mathrm{C}$ terminal SCR15-SCR20, especial SCR20 [34], and 2 mutations were detected in this study. These sites primarily mediate surface binding and target recognition. The other mutations were at SCR1-SCR4, where the CFH family helps the binding of $\mathrm{C} 3$ and heparin-like oligosaccharides.

The phenotype-genotype correlation of aHUS often has clinical significance. Age-of-onset and disease severity correlate with mutation type as well as response to plasma exchange therapy and outcomes following renal transplantation. In this study, complement mutations were associated with decreased levels of plasma C3. The complement mutations were also associated with renal survival, but it is difficult to draw a conclusion based on a limited number of patients. In addition, the activation of the complement alternative pathway is tightly regulated by a number of circulating and cell-bound complement regulatory proteins. $\mathrm{C} 3 \mathrm{~b}, \mathrm{CFB}, \mathrm{CFD}$ and properdin stabilize and activate the $\mathrm{C} 3$ convertase, whereas $\mathrm{CFH}$, CFHR1-5, CFI, MCP and THBD inhibit or regulate the complement pathway in the fluid-phase or on the surface of host cells. A dynamic balance between complement activation and inactivation exists. Genetic mutations primarily lead to the dysfunction of target genes, and complement mutations in different genes play diverse role in aHUS. In the study, CFH mutation carriers exhibited a trend of early loss of the kidney, whereas patients with MCP mutations remained alive and dialysis-free in a long-term follow-up. Patients with CFH mutations were also reported with a bad prognosis [41]. Thus, understanding the functions of the mutations in certain genes and the whole complement system is critical for clinical evaluation not just for screening. In addition, genetic de- 
fect often increases the susceptibility and further infection or other injury will lead to the development of aHUS. This is a well-known theory of disease, 'second attack', which was first proposed with regard to cancers. In this study, we observed that 10 patients had fever in the disease history. More environmental factors evaluated would enhance understanding of the mechanism and show therapy insight for clinicians.

In summary, the prevalence of genetic variation was evaluated in Chinese aHUS patients. Understanding the genetic background in China would facilitate the clinical management of aHUS patients in this region. However, our study only involved 23 patients. The small sample size might lead to analysis bias and reduce the significance of findings. The published cohort from Japan, the only oth- er study published from Asia, enrolled only 10 patients. More studies are needed to understand this issue in Asia, including genetic profiles and genotype-phenotype associations.

\section{Acknowledgments}

We thank all the patients and their families who participated in this study. This work was supported by grants from National Natural Science Foundation of China (No. 81570714 and 81370788).

\section{Disclosure Statement}

None declared.

\section{References}

1 Noris M, Remuzzi G: Atypical hemolytic-uremic syndrome. N Engl J Med 2009;361361: 1676-1687.

2 Taylor CM, Chua C, Howie AJ, Risdon RA: Clinico-pathological findings in diarrhoeanegative haemolytic uraemic syndrome. Pediatr Nephrol 2004;19:419-425.

3 Kavanagh D, Goodship TH: Atypical hemolytic uremic syndrome. Curr Opin Hematol 2010;17:432-438

4 Loirat C, Noris M, Fremeaux-Bacchi V: Complement and the atypical hemolytic uremic syndrome in children. Pediatr Nephrol 2008; 23:1957-1972.

5 Kavanagh D, Richards A, Fremeaux-Bacchi V, Noris M, Goodship T, Remuzzi G, Atkinson JP: Screening for complement system abnormalities in patients with atypical hemolytic uremic syndrome. Clin J Am Soc Nephrol 2007;2:591-596.

6 Roumenina LT, Loirat C, Dragon-Durey MA, Halbwachs-Mecarelli L, Sautes-Fridman C, Fremeaux-Bacchi V: Alternative complement pathway assessment in patients with atypical HUS. J Immunol Methods 2011;365:8-26.

7 Sethi S, Fervenza FC: Membranoproliferative glomerulonephritis - a new look at an old entity. N Engl J Med 2012;366:1119-1131.

8 Bresin E, Rurali E, Caprioli J, Sanchez-Corral $\mathrm{P}$, Fremeaux-Bacchi V, Rodriguez De Cordoba S, Pinto S, Goodship TH, Alberti M, Ribes D, Valoti E, Remuzzi G, Noris M: Combined complement gene mutations in atypical hemolytic uremic syndrome influence clinical phenotype. J Am Soc Nephrol 2013;24:475486.

9 Sullivan M, Erlic Z, Hoffmann MM, Arbeiter K, Patzer L, Budde K, Hoppe B, Zeier M, Lhotta K, Rybicki LA, Bock A, Berisha G, Neumann HP: Epidemiological approach to identifying genetic predispositions for atypical he- molytic uremic syndrome. Ann Hum Genet 2010;74:17-26.

10 Lemaire M, Fremeaux-Bacchi V, Schaefer F, Choi M, Tang WH, Le Quintrec M, Fakhouri F, Taque S, Nobili F, Martinez F, Ji W, Overton JD, Mane SM, Nurnberg G, Altmuller J, Thiele H, Morin D, Deschenes G, Baudouin V, Llanas B, Collard L, Majid MA, Simkova E, Nurnberg P, Rioux-Leclerc N, Moeckel GW, Gubler MC, Hwa J, Loirat C, Lifton RP: Recessive mutations in DGKE cause atypical hemolytic-uremic syndrome. Nat Genet 2013;45: 531-536.

11 Fan X, Yoshida Y, Honda S, Matsumoto M, Sawada Y, Hattori M, Hisanaga S, Hiwa R, Nakamura F, Tomomori M, Miyagawa $\mathrm{S}, \mathrm{Fu}-$ jimaru R, Yamada H, Sawai T, Ikeda Y, Iwata N, Uemura O, Matsukuma E, Aizawa Y, Harada $\mathrm{H}$, Wada $\mathrm{H}$, Ishikawa $\mathrm{E}$, Ashida $\mathrm{A}$, Nangaku M, Miyata T, Fujimura Y: Analysis of genetic and predisposing factors in Japanese patients with atypical hemolytic uremic syndrome. Mol Immunol 2013;54:238-246.

12 Wang F, Zhang L, Wang H: Awareness of CKD in China: a national cross-sectional survey. Am J Kidney Dis 2014;63:1068-1070.

13 Kaplan BS, Meyers KE, Schulman SL: The pathogenesis and treatment of hemolytic uremic syndrome. J Am Soc Nephrol 1998;9: 1126-1133.

14 Noris M, Remuzzi G: Hemolytic uremic syndrome. J Am Soc Nephrol 2005;16:10351050.

15 Levey AS, Coresh J, Balk E, Kausz AT, Levin A, Steffes MW, Hogg RJ, Perrone RD, Lau J, Eknoyan G: National kidney foundation practice guidelines for chronic kidney disease: evaluation, classification, and stratification. Ann Intern Med 2003;139:137-147.

16 Lin H, Lei Y, Zhang B, Dai Z, Lu X: Common variants of HTR1A and SLC6A4 confer the increasing risk of Schizophrenia susceptibility: a population-based association and epistasis analysis. Am J Med Genet B Neuropsychiatr Genet 2015;168:749-755.

17 Caprioli J, Noris M, Brioschi S, Pianetti G, Castelletti F, Bettinaglio P, Mele C, Bresin E, Cassis L, Gamba S, Porrati F, Bucchioni S, Monteferrante G, Fang CJ, Liszewski MK, Kavanagh D, Atkinson JP, Remuzzi G: Genetics of HUS: the impact of MCP, CFH, and IF mutations on clinical presentation, response to treatment, and outcome. Blood 2006;108: 1267-1279.

18 Maga TK, Nishimura CJ, Weaver AE, Frees KL, Smith RJ: Mutations in alternative pathway complement proteins in American patients with atypical hemolytic uremic syndrome. Hum Mutat 2010;31:E1445-E1460.

19 Weis JH, Morton CC, Bruns GA, Weis JJ, Klickstein LB, Wong WW, Fearon DT: A complement receptor locus: genes encoding $\mathrm{C} 3 \mathrm{~b} / \mathrm{C} 4 \mathrm{~b}$ receptor and C3d/Epstein-Barr virus receptor map to 1q32. J Immunol 1987; 138:312-315.

20 Heine-Suner D, Diaz-Guillen MA, de Villena FP, Robledo M, Benitez J, Rodriguez de Córdoba S: A high-resolution map of the regulator of the complement activation gene cluster on $1 \mathrm{q} 32$ that integrates new genes and markers. Immunogenetics 1997;45:422-427.

21 Tawadrous H, Maga T, Sharma J, Kupferman J, Smith RJ, Schoeneman M: A novel mutation in the complement factor $\mathrm{B}$ gene (CFB) and atypical hemolytic uremic syndrome. $\mathrm{Pe}$ diatr Nephrol 2010;25:947-951.

22 Rodriguez De Córdoba S, Esparza-Gordillo J, Goicoechea De Jorge E, Lopez-Trascasa M, Sanchez-Corral P: The human complement factor $\mathrm{H}$ : functional roles, genetic variations and disease associations. Mol Immunol 2004; 41:355-367. 
23 Warwicker P, Goodship TH, Donne RL, Pirson Y, Nicholls A, Ward RM, Turnpenny P, Goodship JA: Genetic studies into inherited and sporadic hemolytic uremic syndrome. Kidney Int 1998;53:836-844.

24 Despriet DD, van Duijn CM, Oostra BA, Uitterlinden AG, Hofman A, Wright AF, ten Brink JB, Bakker A, de Jong PT, Vingerling JR, Bergen AA, Klaver CC: Complement component $\mathrm{C} 3$ and risk of age-related macular degeneration. Ophthalmology 2009;116:474-480.e2.

25 Finn JE, Zhang L, Agrawal S, Jayne DR, Oliveira DB, Mathieson PW: Molecular analysis of C3 allotypes in patients with systemic vasculitis. Nephrol Dial Transplant 1994;9: 1564-1567.

26 Despriet DD, Klaver CC, van Duijn CC, Janssens AC: Predictive value of multiple genetic testing for age-related macular degeneration. Arch Ophthalmol 2007;125:1270-1271.

27 Milder FJ, Gomes L, Schouten A, Janssen BJ, Huizinga EG, Romijn RA, Hemrika W, Roos A, Daha MR, Gros P: Factor B structure provides insights into activation of the central protease of the complement system. Nat Struct Mol Biol 2007;14:224-228.

28 Kavanagh D, Richards A, Noris M, Hauhart R, Liszewski MK, Karpman D, Goodship JA, Fremeaux-Bacchi V, Remuzzi G, Goodship TH, Atkinson JP: Characterization of mutations in complement factor I (CFI) associated with hemolytic uremic syndrome. Mol Immunol 2008;45:95-105.

29 Le Quintrec M, Zuber J, Moulin B, Kamar N, Jablonski M, Lionet A, Chatelet V, Mousson C, Mourad G, Bridoux F, Cassuto E, Loirat C, Rondeau E, Delahousse M, Fremeaux-Bacchi $\mathrm{V}$ : Complement genes strongly predict recurrence and graft outcome in adult renal transplant recipients with atypical hemolytic and uremic syndrome. Am J Transplant 2013;13: 663-675.

30 Schramm EC, Roumenina LT, Rybkine T, Chauvet S, Vieira-Martins P, Hue C, Maga T, Valoti E, Wilson V, Jokiranta S, Smith RJ, Noris M, Goodship T, Atkinson JP, Fremeaux-Bacchi V: Mapping interactions between complement $\mathrm{C} 3$ and regulators using mutations in atypical hemolytic uremic syndrome. Blood 2015;125:2359-2369.

31 Martinez-Barricarte R, Heurich M, LopezPerrote A, Tortajada A, Pinto S, LopezTrascasa M, Sanchez-Corral P, Morgan BP, Llorca O, Harris CL, Rodriguez De Córdoba $\mathrm{S}$ : The molecular and structural bases for the association of complement C3 mutations with atypical hemolytic uremic syndrome. Mol Immunol 2015;66:263-273.

32 Janssen BJ, Huizinga EG, Raaijmakers HC, Roos A, Daha MR, Nilsson-Ekdahl K, Nilsson B, Gros P: Structures of complement component $\mathrm{C} 3$ provide insights into the function and evolution of immunity. Nature 2005;437: 505-511.

33 Adriani KS, Brouwer MC, Geldhoff M, Baas F, Zwinderman AH, Paul Morgan B, Harris CL, van der Ende A, van de Beek D: Common polymorphisms in the complement system and susceptiblity to bacterial meningitis. J Infect 2013;66:255-262.

34 Rodriguez E, Rallapalli PM, Osborne AJ, Perkins SJ: New functional and structural insights from updated mutational databases for complement factor $\mathrm{H}$, factor I, membrane cofactor protein and C3. Biosci Rep 2014; 34:pii:e00146.

35 Fang CJ, Fremeaux-Bacchi V, Liszewski MK, Pianetti G, Noris M, Goodship TH, Atkinson JP: Membrane cofactor protein mutations in atypical hemolytic uremic syndrome (aHUS), fatal Stx-HUS, C3 glomerulonephritis, and the HELLP syndrome. Blood 2008;111:624-632.

36 Marinozzi MC, Vergoz L, Rybkine T, Ngo S, Bettoni S, Pashov A, Cayla M, Tabarin F, Jablonski M, Hue C, Smith RJ, Noris M, Halbwachs-Mecarelli L, Donadelli R, FremeauxBacchi V, Roumenina LT: Complement factor B mutations in atypical hemolytic uremic syndrome-disease-relevant or benign? J Am Soc Nephrol 2014;25:2053-2065.

37 Salvadori M, Bertoni E: Update on hemolytic uremic syndrome: diagnostic and therapeutic recommendations. World J Nephrol 2013;2: 56-76.

38 Noris M, Caprioli J, Bresin E, Mossali C, Pianetti G, Gamba S, Daina E, Fenili C, Castelletti F, Sorosina A, Piras R, Donadelli R, Maranta R, van der Meer I, Conway EM, Zipfel PF, Goodship TH, Remuzzi G: Relative role of genetic complement abnormalities in sporadic and familial aHUS and their impact on clinical phenotype. Clin J Am Soc Nephrol 2010; 5:1844-1859.

39 Gale DP, de Jorge EG, Cook HT, MartinezBarricarte R, Hadjisavvas A, McLean AG Pusey CD, Pierides A, Kyriacou K, Athanasiou Y, Voskarides K, Deltas C, Palmer A, Fremeaux-Bacchi V, de Cordoba SR, Maxwell $\mathrm{PH}$, Pickering MC: Identification of a mutation in complement factor $\mathrm{H}$-related protein 5 in patients of cypriot origin with glomerulonephritis. Lancet 2010;376:794-801.

40 Jozsi M, Zipfel PF: Factor H family proteins and human diseases. Trends Immunol 2008; 29:380-387.

41 Remuzzi G, Ruggenenti P, Codazzi D, Noris M, Caprioli J, Locatelli G, Gridelli B: Combined kidney and liver transplantation for familial haemolytic uraemic syndrome. Lancet 2002;359:1671-1672. 